\title{
ELECTRON PARAMAGNETIC RESONANCE $\mathrm{OF} \mathrm{Cr}^{3+} \mathrm{IN} \mathrm{Rb}\left(\mathrm{NH}_{4}\right)_{1-x} \mathrm{Al}\left(\mathrm{SO}_{4}\right)_{2} \cdot 12 \mathrm{H}_{2} \mathrm{O}$
}

\author{
S. TAKHUR and V.K. JAIN \\ Department of Physics, M.D. University, Rohtak, Rohtak-124001, India
}

(Received March 3, 1994)

The EPR of $\mathrm{Cr}^{3+}$ in mixed alum $\mathrm{Rb}_{x}\left(\mathrm{NI}_{4}\right)_{1-x} \mathrm{Al}\left(\mathrm{SO}_{4}\right)_{2} \cdot 12 \mathrm{H}_{2} \mathrm{O}$ has been studied at $c a .300 \mathrm{~K}$ and $c a$. $9.45 \mathrm{GHz}$. The EPR spectrum for $x$ between 30 to $70 \%$ slows more than one kind of chromium complexes. The variation in magnitude of zero-ficld splitting parameter $D$ indicates that the monovalent ions probably play an important role in the trigonal distortion of the water octahedron around the trivalent metal ion in alums.

PACS numbers: $76.30 . \mathrm{Fc}$

\section{- 1. Introduction}

The alum with the general formula $\mathrm{M}^{1+} \mathrm{M}^{3+}\left(\mathrm{XO}_{4}\right)_{2} \cdot 12 \mathrm{I}_{2} \mathrm{O}(\mathrm{X}=\mathrm{S}, \mathrm{Se})$, where $\mathrm{M}^{1+}$ is a monovalent cation $\left(\mathrm{NI}_{4}, \mathrm{~K}, \mathrm{Rb}, \mathrm{Cs}, \mathrm{Tl}\right)$ and $\mathrm{M}^{3+}$ is a trivalent cation $(\mathrm{Al}, \mathrm{Ga}, \mathrm{In}, \mathrm{Cr}, \mathrm{Fe})$, forms an interesting isomorphous series of salts. It is easy to prepare a solid solution of the paramagnetic salts in diamagnetic ones over a wide range (0-100\%) of relative concentration. There has been a considerable interest in the electron paramagnetic resonance (EPR) of these salts because they contributed significantly to understanding of the location of a paramagnetic ion, high order transitions and phase transitions [1-5]. In this paper we report the EPR of $\mathrm{Cr}^{3+}$ diluted in a solid solution of $\mathrm{RbAl}\left(\mathrm{SO}_{4}\right)_{2} \cdot 12 \mathrm{II}_{2} \mathrm{O}$ and $\mathrm{NII}_{4} \mathrm{Al}\left(\mathrm{SO}_{4}\right)_{2} \cdot 12 \mathrm{H}_{2} \mathrm{O}$. The present study has been undertaken in order to understand the effect of the monovalent ion on the zero-field splitting (ZFS) parameter $D$. The EPR of $\mathrm{Cr}^{3+}$ has been previously studied in $\mathrm{NI}_{4} \mathrm{Al}\left(\mathrm{SO}_{4}\right)_{2} \cdot 12 \mathrm{II}_{2} \mathrm{O}$ [1] and $\mathrm{RbAl}\left(\mathrm{SO}_{4}\right)_{2} \cdot 12 \mathrm{II}_{2} \mathrm{O}$ [2].

\section{Crystal structure}

The alums belong to the cubic system with a space group $T_{h}^{6}(\mathrm{~Pa} 3)$. Because of different atomic arrangements they exist in three types, namely $\alpha, \beta$ and $\gamma$ [6]. The $\mathrm{Rb}$ alum and the $\mathrm{NH}_{4}$ alum belong to $\alpha$ type. The lattice constant $a$ of $\mathrm{Rb}$ alum is $1.2243 \mathrm{~nm}$ [7] and of $\mathrm{NII}_{4}$ alum is $1.2240 \mathrm{~nm}$ [7]. The unit cell contains four formula units. The $\mathrm{Al}^{3+}$ has six water molecules as nearest neighbour forming a 
nearly regular octahedron. On the other hand the octahedron of water molecules about the $\mathrm{M}^{1+}$ is strongly distorted. The six near neighbour $\mathrm{M}^{1+}$ sites about an $\mathrm{M}^{3+}$ are octahedrally disposed while the second neighbour $\mathrm{M}^{1+}$ sites are eight-fold cubic. The [111] axis of the octahedron surrounding $\mathrm{Al}^{3+}$ coincides with the [111] axis of the crystal, but the axcs of the octahedron deviate from the cubic axes of the crystal by an angle of rotation $c a .9 .5^{\circ}$ about the [111] direction.

\section{Experimental}

Single crystals of $\mathrm{Rb}_{x}\left(\mathrm{NII}_{4}\right)_{1-x} \mathrm{Al}\left(\mathrm{SO}_{4}\right)_{2} \cdot 12 \mathrm{II}_{2} \mathrm{O}(x=0.1$ to 0.9$)$ were grown at $\simeq 300 \mathrm{~K}$ by slow evaporation of the salurated aqueous solution of the component alums. $\mathrm{Cr}^{3+}$ was introduced in to the host lattice by adding chromic sulphate (1\% by weight).

The EPR experiments were performed on a JEOL FE-3X homodyne spectrometer operating at $\simeq 9.45 \mathrm{GIz}$ equipped with a $\mathrm{TE}_{011}$ cylindrical cavity and $100 \mathrm{kIIz}$ field modulation. $A$ speck of powdered DPPII used as a field marker (taking $g_{\text {DPPII }}=2.0036$ ) was inserted simultaneously into the sample cavity. The crystals were mounted on quartz rods. The angular variation studies were made using a JES-UCR-2X sample rotating device. Powder spectra were recorded by taking powder in quartz lubes. Each powdered EPR sample was obtained by grinding an individual untwimned crystal.

\section{Results and discussion}

For an arbitrary orientation of the crystal, the EPR spectrum consists of a 1 umber of intense lines besides some weak lines at low magnetic field side of the spectrum in all the crystals studied. Angular variation studies reveal the presence of four magnetically inequivalent but otherwise identical $\mathrm{Cr}^{3+}$ complexes (formed by the substitution of $\mathrm{Al}^{3+}$ by $\mathrm{Cr}^{3+}$ ) with their $z$ axes along the $\langle 111\rangle$ direction. The EPR spectrum shows an axial symmetry about the $z$ axis. The samples having rubidium concentration betwecn 30-70\% show the evidence of another chromium complexe (Fig. 1). It is observed that along the $z$ axis, $M= \pm 3 / 2 \rightarrow \pm 1 / 2$ transitions are not single lines but there is a second broader spectrum in the wings which would give a ZFS different from the $M= \pm 3 / 2 \rightarrow \pm 1 / 2$ of intense spectrum. The weak lines at low magnetic field side of the spectrum are identified as high order EPR transitions of $\mathrm{Cr}^{3+}$ [1]. Powdered spectra have also been recorded for all the samples.

The EPR measurements on $\mathrm{Rb}_{x}\left(\mathrm{NII}_{4}\right)_{1-x} \mathrm{Al}\left(\mathrm{SO}_{4}\right)_{2} \cdot 12 \mathrm{H}_{2} \mathrm{O}$ were analysed using the spin-IIamiltonian appropriate for $\mathrm{Cr}^{3+}$ in an axial crystalline field [1]

$$
\mathcal{H}=\beta_{\mathrm{e}} S g B+D\left[S_{z}^{2}-(1 / 3) S(S+1)\right],
$$

where the terms have their usual meaning. The $g$-factor is isotropic within the experimental error and $S=3 / 2$ for $\mathrm{Cr}^{3+}$.

The parameter $D$ and $g$ have been evaluated using the resonance field positions [1] of the above spin-IIamiltonian. The $g$ values in all the samples studied lie in the range of $1.977 \pm 0.005$. The sign of $D$ was taken to be positive in accordance with the results of Manoogian and Leclerc [2]. The value of $D$ for different 


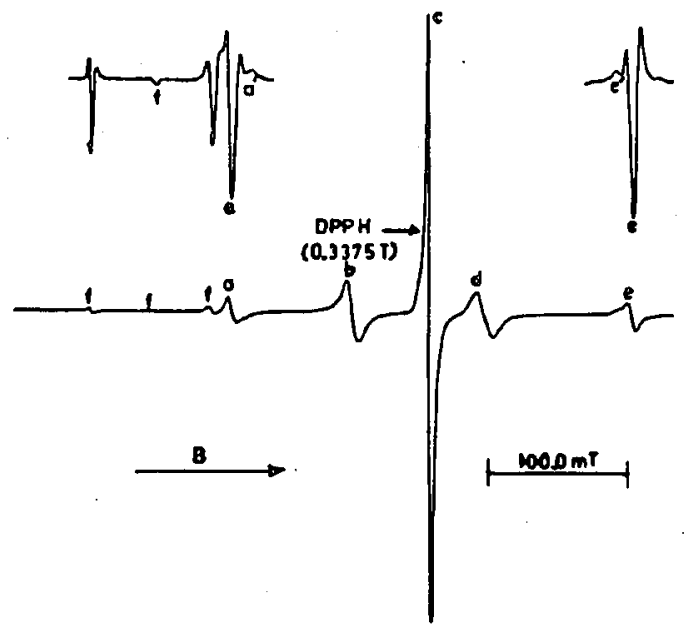

Fig. 1. The $z$ axis room temperature $(300 \mathrm{~K})$ spectrum of $\mathrm{Cr}^{3+}$ in $\mathrm{Rb}_{x}\left(\mathrm{NH}_{4}\right)_{1-x} \mathrm{Al}\left(\mathrm{SO}_{4}\right)_{2} \cdot 12 \mathrm{H}_{2} \mathrm{O}$ single crystals $(x=0.5)$. The lines marked a, $\mathrm{a}^{\prime}, \mathrm{e}, \mathrm{e}^{\prime}$, are single, $b$ and $\mathbf{d}$ triple and c consists of four lines. The lines belonging to $z$ axis of intense chromium complex are $a, e$ and one of $c, a^{\prime}$ and $e^{\prime}$ belong to $z$ axis of the weak chromium complex. The letter $f$ represent high order EPR transitions of the intense $\mathrm{Cr}^{3+}$ centres different from the one whose three fine structure lines are a, e and $\mathrm{c}$. The amplified lines are recorded as a second derivative.

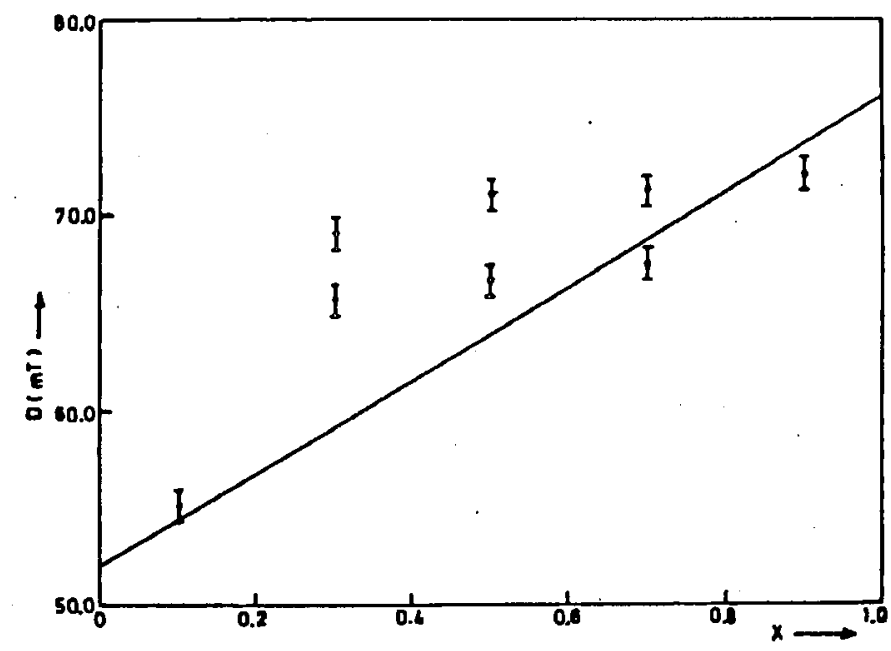

Fig. 2. Zero-field splitting parameter $D$ for $\mathrm{Cr}^{3+}$ in $\mathrm{Rb}_{x}\left(\mathrm{NH}_{4}\right)_{1-x} \mathrm{Al}\left(\mathrm{SO}_{4}\right)_{2} \cdot 12 \mathrm{II}_{2} \mathrm{O}$ vs. $x$ at $300 \mathrm{~K}$.

composition of the samples are shown graphically in Fig. 2. A straight line been drawn through the points representing the value of $D$ of $\mathrm{Cr}^{3+}$ in the pure alums $[1,2]$. It is found that the ZFS parameter $D$ of all the $\mathrm{Cr}^{3+}$ complexes in mixed 
alums lies between those of pure rubidium and ammonium alums. The results suggest that we observe a scries of discrete spectra corresponding to different local crystalline environment. Since local distortion of the primary coordination shell of the paramagnetic ion controls the ZFS, onc would expect a different spectrum for each set of mixed neighbours and perhaps further differentiation due to the second neighbour substitution. The variation of the EPR spectra with composition is probably a sequential growth and diminuting of discrete spectra corresponding to the specific configuration of near neighbours.

Chand et al. [8] have studied the EPR of $\mathrm{Cr}^{3+}$ in mixed alums $\left(\mathrm{NI}_{4}\right)_{x} \mathrm{M}_{1-x} \mathrm{Al}\left(\mathrm{SO}_{4}\right)_{2} \cdot 12 \mathrm{H}_{2} \mathrm{O}(\mathrm{M}=\mathrm{Na}, \mathrm{K})$ and have observed only one specie. This would imply that the trigonal distortion about the chromium ion (at the $\mathrm{Al}$ site) depends on the average occupancy of neighbouring $\mathrm{M}^{1+}$ sites. However, this supposition is not in accordance with the assumption that the local distortion of the primary coordination shell of the paramagnetic ion controls the ZFS. Thus one would expect a different EPR spectrum for each set of mixed near neighbours and perhaps further differention due to the second neighıbour substitution. One reason for not observing the multiplet spectra by Chand et al. [8] is probably due to the fact that the component of species is not resolved because of a small difference in the values of the ZFS of $\mathrm{Cr}^{3+}$ in pure alums and a large linewidth.

\section{Acknowledgments}

This work is supported by C.S.I.R. New Dellii.

\section{References}

[1] S. Dlıanuskodi, N. ITarilıaran, Acta Pliys. Pol. A 70, 347 (1986).

[2] A. Manoogian, A. Leclerc, J. Chem. Phys. 63, 4450 (1976); A. Leclerc, A. Manoogian, J. Chem. Phys. 63, 4456 (1975); V.K. Jain, P. Venkateswarlu, Mol. Phys. 36, 1577 (1978).

[3] P.J. Brandt, Phys. Rev. B 2, 4366 (1970); S. Radhakrishna, T. Bhaskar Rao, Phys. Stalus Solidi A 35, 715 (1976).

[4] R. Büsher, G. Lelınann, Z. Nal.forsch. A 42, 67 (1987).

[5] D.E.O. Reilly, T. Tsang, Phys. Rev. 157, 417 (1967); S. Sinha, R. Srinivasan, Chem. Phys. Lelt. 88, 115 (1982); S. Sinha, R. Srinivasan, J. Phys. Chem. Solids 45, 665 (1984); S. Sinha, R. Sriuivasan, Pramana 22, 345 (1984); K. Biclecki, Z. Kruczynski, S.I. Farcas, Phys. Slatus Solidi B 141, K67 (1987).

[6] H. Lipson, C.A. Beevers, Proc. R. Soc. (Lond.) A 148, 664 (1935); H. Lipson, Proc. R. Soc. (Lond.) A 151, 347 (1935).

[7] R.W.G. Wyckoff, Crystal Structures, 2nd ed., Vol. 3, Interscience, New York 1965, p. 875; A.C. Larson, D:T. Cromer, Acla Crystallogr. 22, 793 (1967).

[8] P. Chand, R.M. Kírishna, S.V.J. Lakshman, Solid State Commun. 71, 537 (1989). 